\title{
The epidemiology of Guillain-Barré Syndrome in U.S. military personnel: a case-control study Laura Nelson ${ }^{1}$, Robert Gormley², Mark S Riddle ${ }^{2}$, David R Tribble ${ }^{3}$ and Chad K Porter*2
}

Address: ${ }^{1}$ School of Public Health and Health Services, George Washington University, Washington, DC, USA, ${ }^{2}$ Enteric Diseases Department, Naval Medical Research Center, Silver Spring, Maryland, USA and 3 Infectious Diseases Clinical Research Program, Uniformed Services University of the Health Sciences, Bethesda, Maryland, USA

Email: Laura Nelson - lauraenelson@gmail.com; Robert Gormley - robert.gormley@med.navy.mil; Mark S Riddle - mark.riddle@med.navy.mil; David R Tribble - dtribble@usuhs.mil; Chad K Porter* - chad.porter@med.navy.mil

* Corresponding author

Published: 26 August 2009

BMC Research Notes 2009, 2:171 doi:|0.1/86/1756-0500-2-17|
Received: 22 June 2009

Accepted: 26 August 2009

This article is available from: http://www.biomedcentral.com/1756-0500/2/17।

(C) 2009 Porter et al; licensee BioMed Central Ltd.

This is an Open Access article distributed under the terms of the Creative Commons Attribution License (http://creativecommons.org/licenses/by/2.0), which permits unrestricted use, distribution, and reproduction in any medium, provided the original work is properly cited.

\begin{abstract}
Background: Guillain-Barré Syndrome (GBS), the leading cause of acute flaccid paralysis worldwide, is an autoimmune disorder involving the loss of the myelin sheaths encasing peripheral nerve axons, leading to a loss of nerve signaling and typically ascending paralysis. A number of infectious triggers have been identified, with Campylobacter being most common. Limited data are available regarding GBS in U.S. service members at a high risk of exposure to numerous GBSassociated infectious agents.

Findings: Medical encounter data were obtained from the Armed Forces Health Surveillance Center (Silver Spring, MD). Active duty personnel with an incident GBS diagnosis were matched by age, sex, and time with up to 4 controls. Demographic, antecedent infectious gastroenteritis (IGE), and deployment covariates were used to explore GBS risk in this population.

The overall incidence was $2.28 / 100,000$ persons (95\% confidence interval: $2.03-2.54$ ) with $19.1 \%$ $(60 / 3 / 4)$ receiving GBS-related medical care for more than one year. The majority of cases were male, Caucasian and under 25 years of age. There was an increased risk of GBS three months following a documented episode of IGE (Odds Ratio: 5.33; $p=0.03$ ). We also found an association with service in the Air Force and Navy (compared to Army personnel) with odds ratios of 1.39 ( $P$ $=0.05)$ and $\mathrm{I} .44(\mathrm{p}=0.02)$, respectively.

Conclusion: GBS incidence in the U.S. military is slightly higher than the general population and is associated with an antecedent IGE. Future studies are warranted to assess whether there are GBSassociated infectious or environmental exposures inherent to military populations.
\end{abstract}

\section{Background}

Guillain-Barré Syndrome (GBS) is the leading cause of acute flaccid paralysis with an estimated worldwide incidence of 1.1-1.8/100,000 persons and has been associ- ated with $\$ 1.7$ billion in yearly costs in the United States alone $[1,2]$. Cases range from mild to severe disease and recovery depends on disease severity. Symptoms usually take 6 to 18 months to fully resolve, although a small pro- 
portion may require prolonged hospitalization or care [35].

The association between GBS and antecedent infection has been well described, with Campylobacter jejuni, Cytomegalovirus (CMV), and Epstein-Barr virus (EBV) commonly identified and C. jejuni being by far the most frequent [6-11]. Interestingly, C. jejuni-associated GBS may be associated with a more severe clinical presentation [12].

Campylobacter is a leading bacterial cause of IGE worldwide [13]. A number of studies also document $C$. jejuni as a leading cause of travelers' diarrhea (TD) in U.S. military personnel, particularly in Southeast Asia [14-16]. Additionally, military personnel are exposed to numerous deployment-related vaccinations [17], which have also been linked to several autoimmune diseases including GBS $[18,19]$.

Little data on GBS epidemiology in military populations are available. Using data from the Defense Medical Surveillance System (DMSS), from 1998 to 2007, we identified incident cases of GBS in active duty military personnel and, utilizing a match case-control study design, evaluated the association between GBS and acute gastrointestinal infection and deployment.

\section{Methods}

Data were obtained from the Armed Forces Health Surveillance Center (AFHSC) which oversees the Defense Medical Surveillance System (DMSS), a database containing all medical encounters at military treatment facilities for all active duty US military from 1998 to the present [20]. Medical information was linked to demographic and deployment databases. Prior to provision of the final dataset for analysis, study identification numbers were assigned and identifiable information was removed.

Cases were active duty US military personnel with a GBS diagnosis (ICD9-CM code 357.0) between 1999 and 2007. We required two separate GBS-associated medical encounters within 1 year of initial diagnosis to increase specificity. Controls ( $\geq 4$ per case) were identified from the same medical encounter dataset, and were matched on age (within 1 year), sex, and time (within 1 year) of an unrelated medical encounter.

Additional covariates evaluated included type of medical visit (inpatient or outpatient), marital status, rank, service type, education and race. An antecedent episode of IGE in the 1 year prior to censure was evaluated as a risk factor for GBS. Deployment to a region of high TD risk (including Iraq, Afghanistan, Southwest Asia and the Persian Gulf) in the year preceding censure was also evaluated as a surrogate for prior IGE.

For each case, all GBS-related medical encounters were evaluated. Cases with a year or more of GBS-related encounters were classified as "chronic". The incidence of GBS (with exact 95\% confidence intervals) was estimated using the number of cases and the number of active duty US military personnel (from the Defense Medical Epidemiology Database). Poisson regression was used to assess temporal changes in incidence. The association between GBS, antecedent IGE, operational deployment and other covariates were explored using univariate conditional logistic regression methods. Odds ratios (OR) were calculated with Wald 95\% confidence intervals. All data were analyzed using SAS v. 9.1 (SAS Institute, Cary, NC) with an alpha of 0.05 .

\section{Results}

The majority of cases were male $(\mathrm{n}=262 ; 83.4 \%)$, between the ages of 20 and $24(\mathrm{n}=101 ; 32.2 \%)$, Caucasian $(\mathrm{n}=210 ; 66.9 \%)$ and single $(\mathrm{n}=153 ; 48.7 \%)$ (table $1)$. Cases and controls were mostly enlisted $(83.4 \%$ and $85.1 \%$, respectively). The majority of cases ( $\mathrm{n}=226$; $72.0 \%)$ and controls $(\mathrm{n}=908 ; 72.3 \%)$ had no more than a high school education. Cases were more commonly Navy personnel $(\mathrm{n}=101 ; 32.2 \%)$ than other branches of service while controls were more commonly in the Army $(\mathrm{n}=466 ; 37.1 \%)$. Controls had no outcomes associated with enteric infections. The most common ICD-9 code for controls was V70.5, a routine health exam, accounting for $10.9 \%$ of included controls. No other single ICD-9 accounted for more than $5 \%$ of the controls.

Overall, GBS incidence was 2.28 (95\% C.I.: 2.03, 2.54) per 100,000 person-years (table 2). The incidence increased from 2.35 in 1999 to 2.94 in 2007 with a spike of cases in 2004 (figure 1). Although no significant changes in GBS incidence were observed over the period of observation, general fluctuations were seen. Navy personnel had the highest incidence of GBS in 5 of 9 (figure 1). Additionally, non-white and non-black females had the highest incidence in five out of nine years with no observable trends. The youngest age category $(<20$ years of age) had an increasing GBS incidence from 1999 to 2005 and had the highest incidence during 4 of those years. Persons $\geq 40$ years of age had a similar increasing trend from 2003 to 2007.

The censoring diagnosis for most cases $(52.5 \%)$ occurred in an outpatient setting although $225(71.7 \%)$ had an inpatient GBS-related medical encounter during the course of their medical care. After initial case presentation, common GBS-related follow-up medical encounters included: physical therapy $(\mathrm{n}=53 ; 16.9 \%)$, occupational 
Table I: Demographic characteristics of U.S. military service members diagnosed with Guillain-Barré Syndrome between 1999 and 2007 and their matched controls

\begin{tabular}{lcc}
\hline & Cases & Controls \\
\hline $\mathrm{N}$ & 314 & 1,256 \\
\hline Agel & $28.7(9.3)$ & $28.6(9.0)$ \\
\hline Fex ${ }^{2}$ & & \\
\hline Male & $52(16.6)$ & $208(16.6)$ \\
\hline Race ${ }^{2}$ & $262(83.4)$ & $1048(83.4)$ \\
\hline Black & & \\
\hline White & $55(17.5)$ & $215(17.1)$ \\
\hline Other & $210(66.9)$ & $794(63.2)$ \\
\hline
\end{tabular}

Marital status 2,3

\begin{tabular}{lcc}
\hline Married & $148(47.1)$ & $555(44.2)$ \\
\hline Single & $153(48.7)$ & $651(51.8)$ \\
\hline Other & $9(2.9)$ & $47(3.7)$ \\
\hline Rank $^{2}$ & & \\
\hline Enlisted & $262(83.4)$ & $1069(85.1)$ \\
\hline Officer & $47(15.0)$ & $177(14.1)$ \\
\hline Warrant Officer & $5(1.6)$ & $10(0.8)$ \\
\hline
\end{tabular}

Service type ${ }^{2}$

\begin{tabular}{lcc}
\hline Army & $93(29.6)$ & $466(37.1)$ \\
\hline Air Force & $80(25.5)$ & $289(23.0)$ \\
\hline Marines & $40(12.7)$ & $147(11.7)$ \\
\hline Navy & $101(32.2)$ & $354(28.2)$ \\
\hline
\end{tabular}

Education level2,4

High school (or equivalent)

$226(72.0) \quad 908(72.3)$ therapy $(\mathrm{n}=24 ; 7.6 \%)$, rehabilitation $(\mathrm{n}=49 ; 15.6 \%)$ and speech therapy $(5 ; 1.6 \%)$.

The median number of GBS-related medical visits is shown in table 2. Although there was a trend toward a higher number of follow-up visits for males, younger cases (those in the 20 year age group), and those of race "other," these differences were not significant. A total of $19.1 \%$ of cases received GBS-related medical care beyond 1 year after initial presentation.

In the three months prior to censure, cases had a higher odds of a documented antecedent IGE compared to matched controls (OR: 5.33; 95\% C.I.: 1.19, 23.82), although no specific IGE etiology was found (Table 3 ). We were unable to identify a significant association between GBS and prior deployment to a region with high TD risk in the year preceding censure. However, 11 cases $(3.5 \%)$ had their initial GBS encounter during a deployment to one of those regions. Compared to their Army counterparts, Air Force (OR: 1.4; 95\% C.I.: 1.0, 1.9) and Navy (OR: $1.4 ; 95 \%$ CI: $1.1,2.0$ ) personnel had a higher odds of GBS. Education also appeared to be associated with an increased odds of GBS with a higher odds in those with doctorate degrees compared to those with no greater than a high school education (OR: 2.28; 95\% CI: 1.00 to 5.23). This association was not observed across other education categories.

\section{Discussion}

We found a slightly higher incidence of GBS (2.3/ $100,000)$ in an active duty U.S. military population compared to the general population estimates of 1.1 to $1.8 /$ 100,000 recently reported [2]. This may represent a true GBS risk among U.S. military personnel due to an increased risk of exposures to known infectious triggers, unknown triggers (infectious or non-infectious), or an artifact of the methodology utilized. McGrogan et al reported that "retrospective database studies" found an overall higher GBS incidence compared to prospective studies or retrospective medical record reviews [2]. This may reflect incomplete or incorrect medical coding in database studies, inadequate case-finding procedures or poorly defined estimates of at risk populations in other study designs. In an effort to minimize coding errors, we required a GBS diagnosis on at least two separate medical encounters, eliminating 285 possible cases and effectively halving our incidence estimate. Of these 285, a majority ( $n=207$ ) had an ICD9-CM of 357.0 in the first diagnostic position and 33 had their lone GBS-related medical encounter at an inpatient facility. Thus, our methodology may have also biased our incidence estimates downward.

We found a bimodal distribution of incidence with highest rates in those under 25 and over 40 years of age. 
Table I: Demographic characteristics of U.S. military service members diagnosed with Guillain-Barré Syndrome between 1999 and 2007 and their matched controls (Continued)

\begin{tabular}{lcc}
\hline Some college & $27(8.6)$ & $95(7.6)$ \\
\hline Bachelor's degree & $27(8.6)$ & $132(10.5)$ \\
\hline Master's degree & $14(4.5)$ & $65(5.2)$ \\
\hline Doctorate degree & $9(2.9)$ & $16(1.3)$ \\
\hline
\end{tabular}

I Mean (standard deviation)

2 Number (percent)

34 cases ( $1.3 \%$ ) and 3 controls $(0.2 \%)$ missing data

${ }^{4} \mathrm{II}$ cases (3.5\%) and 40 controls (3.2\%) missing data

Although the biological mechanisms are uncertain and the epidemiologic data are inconsistent, others have reported similar findings. One hypothesis is that the peak in late adolescence and early adulthood is associated with a secondary peak in $C$. jejuni incidence in that age group (in developed world populations), whereas the peak in an elderly population may be associated with failed immu- nosuppression mechanisms [21]. Others have hypothesized an age-specific differential risk of Campylobacterattributable GBS [10]. Further research is needed to fully understand this effect.

Prior IGE was associated with an increased GBS risk. Although we were unable to attribute this increased risk with a specific organism, the known Campylobacter association is the most likely causative agent [11]. Unfortunately, the utilization of ICD9-CM codes to identify infectious exposures, specifically those of GI origin, is limited by the scarcity of microbiologic work-up completed on reporting patients. This has been well-described and continues to be a source of likely non-differential exposure misclassification in these types of studies [22]. Future research should consider a more extensive case history to identify common triggers within the active duty population.

We found a significant increased odds of GBS among Air Force and Navy personnel (compared to Army), and among those with a doctorate degree (compared to no

Table 2: Incidence of GBS and number of GBS-related medical encounters in U.S. military service members diagnosed between 1999 and 2007 stratified by demographic covariates

\begin{tabular}{|c|c|c|c|c|c|}
\hline Covariate & Incidencel & $\begin{array}{c}\text { Number of GBS- } \\
\text { related medical } \\
\text { visits }^{2}\end{array}$ & $\begin{array}{l}\text { Number of GBS- } \\
\text { related medical visits I } \\
\text { month post-censure }{ }^{2}\end{array}$ & $\begin{array}{l}\text { Number of GBS- } \\
\text { related medical visits I } \\
\text { year post-censure }\end{array}$ & $\begin{array}{c}\text { Number of cases receiving } \\
\text { GBS-related medical care } \\
\text { beyond I year post- } \\
\text { censure }\end{array}$ \\
\hline Female & $2.59(1.93,3.39)$ & $6(3,18)$ & $4(2,8)$ & $6(3,16.5)$ & $13(25 \%)$ \\
\hline Male & $2.22(I .96,2.5 I)$ & $9(4,17)$ & $4(2,9)$ & $8(3,17)$ & 47 (18\%) \\
\hline$<20$ & $3.48(2.47,4.75)$ & $12(7,21)$ & $7(5.12)$ & $12(7,21)$ & $4(10 \%)$ \\
\hline $20-24$ & $2.23(I .82,2.7 I)$ & $10(4,18)$ & $4(2,10)$ & $10(4,18)$ & $15(15 \%)$ \\
\hline $25-29$ & $2.21(1.70,2.83)$ & $6(3,17)$ & $4(2,9)$ & $6(3,16)$ & $9(14 \%)$ \\
\hline $30-34$ & $1.61(1.11,2.26)$ & $5(2,15)$ & $3(2,7)$ & $5(2,15)$ & 7 (2।\%) \\
\hline $35-39$ & $1.73(1.19,2.45)$ & $8.5(3.5,13.5)$ & $2(2,5.5)$ & $7.5(3,12.5)$ & $10(31 \%)$ \\
\hline$>=40$ & $3.29(2.41,4.39)$ & $6.5(3,22)$ & $3(1,9)$ & $5.5(2,20)$ & 15 (33\%) \\
\hline Black & $2.07(1.56,2.70)$ & $8(3,17)$ & $5(2,13)$ & $8(3,17)$ & $8(14 \%)$ \\
\hline White & $2.22(1.93,2.54)$ & $8(4,17)$ & $4(2,9)$ & $8(3,17)$ & 45 (21\%) \\
\hline Other & $2.98(2.21,3.92)$ & $10(3,18)$ & $4(2,10)$ & $10(3,18)$ & $7(14 \%)$ \\
\hline Total & $2.28(2.03,2.54)$ & $8.5(3,17)$ & $4(2,9)$ & $8(3,17)$ & 60 (19.1\%) \\
\hline
\end{tabular}

I Incidence per 100,000 with $95 \%$ exact binomial confidence intervals

2 Presented as a median number of visits with interquartile ranges

${ }^{3}$ Presented number of cases with percent of subgroup 


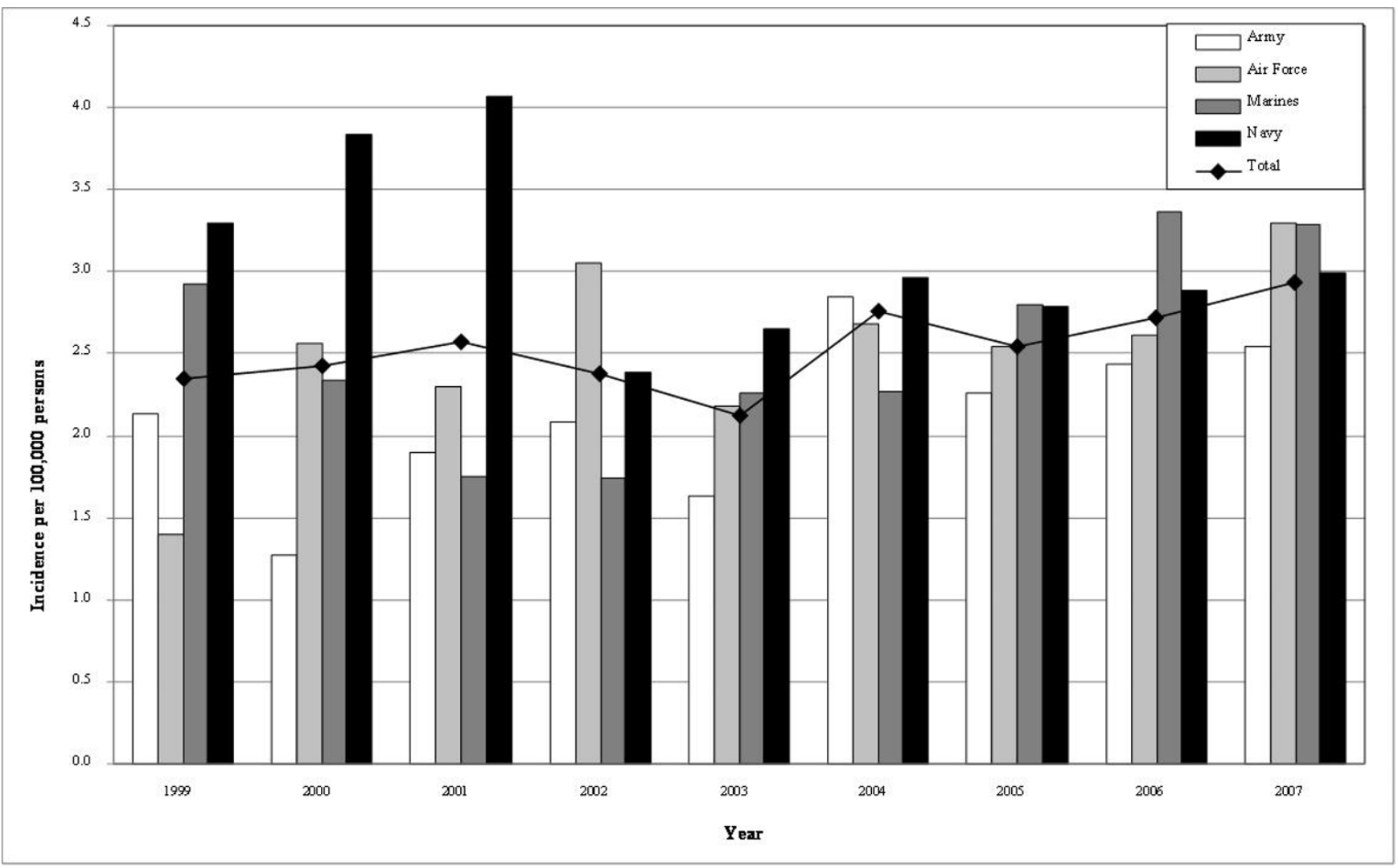

Figure I

Incidence of GBS cases stratified by branch of military service.

more than a high school education). This may reflect a subgroup that was older than the overall study population (mean: 42.9; standard deviation: 9.5) and may disproportionately represent the $\geq 40$ age group, known to have higher GBS rates [21]. Due to age-matching, we were unable to assess age as an independent risk-factor. The association with branch of service has not been previously described. Possible contributing factors could be differences in infectious exposures unique to these 2 branches and further study on the exact etiology of infectious triggers in this population is needed. Additionally, these findings may be associated with differential healthcare utilization in these subgroups. While there is open access to care for all active duty personnel, there may be differential health-seeking behaviors.

GBS is known to cause chronic disability in a minor proportion if cases $[9,21]$. In our study, approximately $20 \%$ of cases had multiple medical visits 1 year post-diagnosis. This may be influenced by the fact that active duty military personnel have essentially unfettered access to free medical care. However, the proportion of "chronic" cases was similar to that reported by Forsberg et al albeit in an older Swedish population [23]. In evaluating the diagnostic codes of follow-on GBS-related medical visits, the most common were associated with physical therapy, rehabilitation, and speech therapy. These data underscore the fact that while GBS sequelae may be rare, the morbidity in terms of loss of function and disability need to be explored and considered when evaluating the importance of infectious disease prevention.

We did not evaluate the differential odds of exposure to other infectious agents with known GBS associations (e.g., $\mathrm{CMV}, \mathrm{EBV})$, nor did we evaluate the association with antecedent vaccination. We did, however, evaluate deployment to military operations in the Middle East and Southwest Asia in the year preceding censure as a potential surrogate for military relevant exposures and found no association with GBS. We were unable to assess peacetime deployments, specifically those to Southeast Asia, an area with high rates of Campylobacter [24-26]. This represents a significant limitation in the utilization of deployment as a surrogate for potentially relevant exposures.

As mentioned, utilizing a medical encounter database has inherent limitations and introduces some biases. First, data coding errors and misclassification are inherent and 
Table 3: Risk factors and covariates associated with GBS among U.S. military personnel diagnosed between 1999 and 2007 stratified by demographic covariates

\begin{tabular}{|c|c|}
\hline Covariate & OR $(95 \% \mathrm{CI})$ \\
\hline \multicolumn{2}{|l|}{ Race } \\
\hline Non-whitel & 1.00 \\
\hline White & $1.17(0.90,1.52)$ \\
\hline \multicolumn{2}{|l|}{ Rank } \\
\hline Enlisted' & 1.00 \\
\hline Officer/Warrant Officer & $1.17(0.80,1.69)$ \\
\hline \multicolumn{2}{|l|}{ Marital status } \\
\hline Not married & 1.00 \\
\hline Married & $1.22(0.89,1.68)$ \\
\hline \multicolumn{2}{|l|}{ Service Type } \\
\hline Army' & 1.00 \\
\hline Air Force & $1.39(1.00,1.95)$ \\
\hline Navy & $1.43(1.05,1.97)$ \\
\hline Marines & $1.38(0.90,2.12)$ \\
\hline
\end{tabular}

\section{Education}

\begin{tabular}{lc}
\hline High school (or equivalent)' & 1.00 \\
\hline Some college & $1.14(0.72,1.8 \mathrm{I})$ \\
\hline Bachelor's degree & $0.83(0.53,1.32)$ \\
\hline Master's degree & $0.87(0.45,1.68)$ \\
\hline Doctorial degree & $2.4 I(0.97,5.95)$ \\
\hline IGE 3 months pre-censure & $5.33(1.19,23.82)$ \\
\hline Deployment 3 months pre-censure ${ }^{2}$ & $0.96(0.56,1.64)$ \\
\hline
\end{tabular}

I Reference category

2 Deployment to Iraq, Afghanistan, Southwest Asia and/or Persian Gulf evaluated such errors are the source of numerous peer-reviewed publications $[27,28]$. Another factor we were unable to assess was infectious exposures occurring during deployment. The DMSS only includes medical encounters at U.S.-based medical treatment facilities. This represents a decreased likelihood of capturing potentially important exposures, including IGE, which occur during deployment limiting the generalizability of these findings. Casefinding and/or seroepidemiologic studies may more accurately identify prior exposures and outcomes and minimize the biases inherent in utilizing medical encounter data.

In summary, this preliminary study found IGE as a trigger for GBS, however questions remain regarding the etiology of such infections, and further study is needed to identify other common and potentially preventable triggers in this population. Regardless, we have described a potentially important infectious sequelae which may not factor in to decreased mission readiness in a deployed operational setting, but may present a significant preventable burden from an individual's and the military health and disability system's perspective.

\section{Competing interests}

The authors declare that they have no competing interests.

\section{Authors' contributions}

MR, CP, DT and RG conceived of the study, and participated in its design and coordination. LN and CP performed data analysis and interpretation and drafted the manuscript. MR and DT participated in data interpretation and manuscript writing. All authors read and approved the final manuscript.

\section{Acknowledgements}

The opinions and assertions herein should not be construed as official or representing the views of the Department of the Navy, Department of the Army, the Department of Defense, or the US Government. This is a US Government work. There are no restrictions on its use. There were no financial conflicts of interests among any of the authors.

Authors are employees of the U.S. Government and military service members. This work was prepared as part of official duties. Title 17 U.S.C. \$105 provides that 'Copyright protection under this title is not available for any work of the United States Government.' Title 17 U.S.C. §I0I defines a U.S. Government work as a work prepared by a military service member or employee of the U.S. Government as part of that person's official duties.

The study protocol was approved by the Naval Medical Research Center Institutional Review Board in compliance with all applicable Federal regulations governing the protection of human subjects.

\section{References}

I. Frenzen PD: Economic cost of Guillain-Barre syndrome in the United States. Neurology 2008, 7 I (I):2I-7. 
2. McGrogan A, Madle GC, Seaman HE, e Vries CS: The epidemiology of Guillain-Barre syndrome worldwide A systematic literature review. Neuroepidemiology 2009, 32(2): 150-63.

3. Ali M, Fernandez-Perez ER, Pendem S, Brown DR, Wijdicks EF, Gajic $O$ : Mechanical ventilation in patients with Guillain-Barre syndrome. Respir Care 2006, 5 I (I 2): 1403-7.

4. Newswanger DL, Warren CR: Guillain-Barre syndrome. Am Fam Physician 2004, 69(10):2405-10.

5. Wijdicks EF, Henderson RD, McClelland RL: Emergency intubation for respiratory failure in Guillain-Barre syndrome. Arch Neurol 2003, 60(7):947-8.

6. Moore JE, et al:: Campylobacter. Vet Res 2005, 36(3):35I-82

7. Mori M, Kuwabara S, Miyake M, Noda M, Kuroki H, Kanno H, Ogawara $\mathrm{K}$, Hattori T: Haemophilus influenzae infection and Guillain-Barre syndrome. Brain 2000, I 23(Pt I0):2|7|-8.

8. Tam CC, O'Brien SJ, Petersen I, Islam A, Hayward A, Rodrigues LC: Guillain-Barre syndrome and preceding infection with campylobacter, influenza and Epstein-Barr virus in the general practice research database. PLoS ONE 2007, 2(4):e344.

9. Winer JB: Guillain Barre syndrome. Mol Pathol 200I, 54(6):38I-5.

10. McCarthy N, Giesecke J: Incidence of Guillain-Barre syndrome following infection with Campylobacter jejuni. Am J Epidemio 200I, I53(6):610-4

II. Tam CC, Rodrigues LC, Petersen I, Islam A, Hayward A, O'Brien S]: Incidence of Guillain-Barre syndrome among patients with Campylobacter infection: a general practice research database study. J Infect Dis 2006, 194(I):95-7.

12. Meche FG Van Der: The Guillain-Barre syndrome; pathogenesis and treatment. Rev Neurol Paris 1996, I 52(5):355-8.

13. Allos BM: Campylobacter jejuni Infections: update on emerging issues and trends. Clin Infect Dis 200I, 32(8): $20 \mathrm{I}-6$.

14. Murphy GS, et al.: Ciprofloxacin and loperamide in the treatment of bacillary dysentery. Ann Intern Med 1993, II 8(8):582-6.

15. Petruccelli BP, et al.: Treatment of traveler's diarrhea with ciprofloxacin and loperamide. J Infect Dis 1992, 165(3):557-60.

16. Echeverria P, et al.: Diarrhea in US troops deployed to Thailand. J Clin Microbiol 1993, 3 I (12):335I-2.

17. U.S. Army Center for Health Promotion and Preventive Medicine. Deployment Medication Information [http:// chppm-www.apgea.army.mil/dmis/]. Accessed April 19, 2009

18. Tishler M, Shoenfeld $Y$ : Vaccination may be associated with autoimmune diseases. Isr Med Assoc J 2004, 6(7):430-2.

19. Vial T, Descotes J: Autoimmune diseases and vaccinations. Eur Jermatol 2004, I 4(2):86-90.

20. Rubertone MV, Brundage JF: The Defense Medical Surveillance System and the Department of Defense Serum Repository: Glimpses of the Future of Public Health Surveillance. American Journal of Public Health 2002, 92(1 2): 1900-1904.

21. Hahn AF: Guillain-Barre syndrome. Lancet 1998 352(9 | 28):635-4I.

22. Hennessy TW, Marcus R, Deneen V, Reddy S, Vugia D, Townes J, Bardsley M, Swerdlow D, Angulo FJ: Survey of physician diagnostic practices for patients with acute diarrhea: clinical and public health implications. Clin Infect Dis 2004, 38(Suppl 3):S203-II.

23. Forsberg A, Press R, Einarsson U, de Pedro-Cuesta J, Holmqvist LW: Disability and health-related quality of life in Guillain-Barre syndrome during the first two years after onset: a prospective study. Clin Rehabil 2005, 19(8):900-9.

24. Padungtod $P$, Kadohira M, Hill G: Livestock production and foodborne diseases from food animals in Thailand. J Vet Med Sc 2008, 70(9):873-9.

25. Sanders JW, et al.: An observational clinic-based study of diarrheal illness in deployed United States military personnel in Thailand: presentation and outcome of Campylobacter infection. Am J Trop Med Hyg 2002, 67(5):533-8.

26. Tribble DR, Baqar S, Pang LW, Mason C, Houng HS, Pitarangsi C, Lebron C, Armstrong A, Sethabutr O, Sanders JW: Diagnostic approach to acute diarrheal illness in a military population on training exercises in Thailand, a region of campylobacter hyperendemicity. J Clin Microbiol 2008, 46(4): I4I 8-25.

27. Peabody JW, Luck J, Jain S, Bertenthal D, Glassman P: Assessing the accuracy of administrative data in health information systems. Med Care 2004, 42(II):1066-72.
28. Miller ML, Wang MC: Accuracy of ICD-9-CM coding of cervical spine fractures: implications for research using administrative databases. Annu Proc Assoc Adv Automot Med 2008, 52:10 I-5.

Publish with Bio Med Central and every scientist can read your work free of charge

"BioMed Central will be the most significant development for disseminating the results of biomedical research in our lifetime. "

Sir Paul Nurse, Cancer Research UK

Your research papers will be:

- available free of charge to the entire biomedical community

- peer reviewed and published immediately upon acceptance

- cited in PubMed and archived on PubMed Central

- yours - you keep the copyright 